\title{
PELATIHAN MANAJEMEN DIABETES MELLITUS BERBASIS BUDAYA SUNDA UNTUK MENINGKATKAN PENGETAHUAN KELUARGA DALAM MERAWAT DIABETISI LANSIA DI TASIKMALAYA
}

\author{
THE TRAINING OF DIABETES MELLITUS MANAGEMENT BASED ON \\ SUNDANESE CULTURE TO IMPROVE FAMILY KONOWLEDGE IN CARING \\ OLDER PEOPLE WITH DIABETES IN TASIKMALAYA
}

\author{
Siti Badriah*, Dini Mariani \\ Jurusan Keperawatan, Poltekkes Kemenkes Tasikmalaya, Jawa Barat, Indonesia \\ Center of Excellent Health And Disaster Emergency (HADE) Center \\ Email: siti.badriah@dosen.poltekkestasikmalaya.ac.id \\ (Diterima 06-01-2021; Disetujui 22-02-2021)
}

\begin{abstract}
ABSTRAK
Penyakit Diabetes Mellitus (DM) merupakan penyakit kronis yang memiliki konotasi budaya karena perilaku hidup yang tidak sehat, sehingga diperlukan upaya untuk meningkatkan perilaku menjadi lebih baik dengan menggunakan pendekatan budaya. Berbagai fenomena yang terjadi pada budaya Sunda menunjukkan perilaku yang berisiko meningkatkan kadar gula darah pada lansia. Oleh karena itu, tujuan dari pengabdian kepada masyarakat ini adalah untuk meningkatkan pengetahuan keluarga dalam merawat diabetisi lansia di Tasikmalaya. Sasaran dari kegiatan pengabdian masyarakat ini adalah pelaku rawat yang merawat diabetisi lansia di rumah. Metode yang digunakan yaitu pelatihan dengan pendekatan budaya Sunda untuk menyampaikan informasi cara perawatan lansia DM di rumah dengan menunjung tinggi nilai-nilai budaya Sunda. Jumlah peserta pelatihan sebanyak 60 orang. Hasil menunjukkan terjadinya peningkatan pengetahuan pelaku rawat setelah diberikan pelatihan. Pelatihan dengan pendekatan budaya Sunda dapat meningkatkan pengetahuan keluarga dalam merawat lansia DM. Disarankan agar pelatihan dengan pendekatan budaya dapat menjadi salah satu alternatif dan teknik meningkatkan pemberdayaan masyarakat dalam merawat lansia diabetes di Indonesia yang memiliki keaneka ragaman budaya.
\end{abstract}

Kata kunci : pelatihan, budaya Sunda, pengetahuan, keluarga, diabetes

\section{ABSTRACT}

Diabetes Mellitus (DM) is a chronic disease that has connotations of culture due unhealthy lifestyle, so to overcome this are needed to improve knowledge for the better by using a cultural approach as well. Various phenomena that occur in Sundanese culture show behaviors that are at risk of increasing blood sugar levels in older people with dibetes, therefore the purpose of this community service is to increase family knowledge in caring older people with diabetes in Tasikmalaya. The target of this community service activity are caregivers who care for older people with diabetes at home. The method used is training with a Sundanese cultural approach to convey information about how to care for older people with diabetes at home by upholding Sundanese cultural values. The number of training participants was 60 people. The results showed an increase in the knowledge of the caregiver after being given training. The training of management diabetes based on Sundanese culture methode can increase family knowledge in caring for older people with diabetes It is recommended that training with a cultural approach can be an alternative and technique to increase community empowerments in caring for older people with diabetes in Indonesia which have cultural diversity.

Keywords: training, Sundanese culture, knowledge, family, diabetes

\section{PENDAHULUAN}

Salah satu indikator keberhasilan pembangunan adalah semakin tingginya usia harapan hidup (UHH). Badan Pusat Statistik (2019) menunjukan adanya kenaikan UHH di Indonesia yaitu dari 70,1 pada tahun 2010; 70,9 pada tahun 2015, dan 71,5 pada tahun 2019. Meningkatnya usia harapan hidup masyarakat Indonesia telah menyebabkan 
Pelatihan Manajemen Diabetes Mellitus Berbasis Budaya Sunda Untuk Meningkatkan Pengetahuan Keluarga Dalam Merawat Diabetisi Lansia Di Tasikmalaya

Siti Badriah, Dini Mariani

proporsi jumlah lansia meningkat dari tahun ke tahun. Hal ini berdampak pada risiko munculnya berbagai masalah kesehatan, salah satunya penyakit Diabetes Mellitus (DM). Riset Kesehatan Dasar (2018) menunjukkan prevalensi diabetes di Indonesia berdasarkan diagnosis dokter menunjukkan bahwa persentase terbanyak kasus DM adalah lansia usia 55-64 tahun yaitu sebesar 6,3\%. Kenyataan ini menunjukan apabila tidak dilakukan program intervensi sebagai upaya pengendalian penyakit DM dikhawatirkan akan terjadi peningkatan kasus diabetes dan berbagai komplikasinya pada lansia di masa yang akan datang.

Berbagai model intervensi baik untuk penderita DM maupun lansia sudah banyak dilakukan diantaranya Rumoharbo, dkk. (2012) model pemberdayaan SESAMA (pola kerjasama antara perawat bersama kader dasawisma serta penyandang prediabetes). Riasmini, dkk. (2013) model kelompok keluarga mandiri (KKM) yang mengintegrasikan kelompok swabantu dan kelompok pendukung untuk lansia. Novieastari, dkk. (2013) model asuhan keperawatan peka budaya terhadap kepuasan pasien DM di Rumah Sakit. Berbagai pendekatan yang dilakukan tersebut lebih dominan pada sistem di luar keluarga dengan memberdayakan kader dan perawat. Sementara pelibatan keluarga sebagai primordial prevention dengan berbasis budaya dalam pengendalian gula darah belum banyak menjadi kajian.

Leininger dan McFarland (2002) dengan trancultural nursing nya menyebutkan beberapa aspek budaya dapat menjadi bahan kajian dalam upaya pemberian asuhan keperawatan. Sementara itu, keluarga sebagai family centre nursing (FCN) memandang bahwa keluarga merupakan unit dasar dalam perawatan anggota keluarga dan menjadi bagian yang sangat berpotensi untuk membantu lansia dalam mengatasi masalah kesehatan, mengubah status kesehatan serta mendukung terhadap perubahan gaya hidup (Friedman, et al, 2010). Oleh karena itu, perawat komunitas harus bekerjasama dengan keluarga untuk mencapai keberhasilan dalam pemberian asuhan kepada anggota keluarga (Stanhope\& Lancaster, 2016) Bentuk kerjasama antara perawat dan keluarga ini selaras dengan filosofi budaya Sunda silih asah, silih asuh, silih asih yaitu saling mengasah kemampuan, saling mengasihi dan saling mengasuh dengan memberikan dukungan pada keluarga yang mempunyai masalah. Berdasarkan hal tersebut, maka diperlukan upaya untuk meningkatkan pengetahuan keluarga dalam merawat lansia diabetes di rumah yang berbasis pada budaya Sunda.

Tasikmalaya merupakan salah satu kota di Provinsi Jawa Barat yang memiliki kasus PTM sebesar 23.885 dengan 570 diantaranya adalah penyakit diabetes (Dinkes Kota 
Tasikmalaya, 2016). Beberapa fenomena ditemukan bahwa demi membuat orang tuanya senang beberapa keluarga pada masyarakat Sunda di Tasikmalaya cenderung mengikuti keinginan lansia termasuk dalam kebiasaan makan yang dapat berisiko meningkatkan kadar gula darah (Badriah \& Sahar 2017; Badriah, dkk.; 2014). Fenomena tersebut menunjukan apabila program dan upaya pengendalian gula darah tidak komprehensif dan hanya terbatas pada penatalaksaan secara individu, tanpa melibatkan keluarga dikhawatirkan peningkatan kasus DM dengan berbagai komplikasi akan terus meningkat.

Keluarga merupakan bagian yang sangat berpotensi untuk membantu lansia dalam mengatasi masalah kesehatannya melalui dukungan terhadap budaya atau kebiasaan pola hidup yang sehat (Friedman, et al, 2010). Hal ini sejalan dengan nilai budaya Sunda yang menempatkan orang tua pada nilai yang tinggi seperti tertuang dalam ungkapan indung tunggul rahayu bapa tangkal darajat (ibu sebagai sumber keselamatan dan bapak sumber kesuksesan). Tingginya nilai orang tua telah menjadikan keluarga-keluarga pada masyarakat Sunda cenderung memanjakan orang tua dan menuruti semua keinginannya sebagai bentuk taat dan patuh terhadap orang tua (Satjadibrata, 2005; Rosidi, 1984; Badriah, dkk., 2019). Fenomena tersebut menunjukan perlunya perubahan pandangan dengan menggunakan pendekatan budaya Sunda silih asah, silih asuh, silih asih yang dilakukan perawat terhadap keluarga dengan cara meningkatkan pengetahuan dalam bentuk pelatihan manajemen perawatan DM. Dengan demikian, tujuan pengabdian msyarakat ini adalah untuk meningkatkan pengetahuan keluarga dalam merawat diabetisi lansia di Tasikmalaya melalui kegiatan pelatihan berbasis budaya Sunda

\section{BAHAN DAN METODE}

Metode yang digunakan dalam pelaksanaan pengabdian masyarakat adalah pelatihan tentang manajemen diabetes dengan menggunakan pendekatan budaya Sunda; silih asah, silih asih, silih asuh pada pelaku rawat diabetisi lansia di rumah. Silih asah artinya saling mengasah dengan mengembangkan kemampuan keluarga dalam merawat lansia DM melalui pemberian informasi tentang manajemen diabetes meliputi perencanaan makan, aktifitas fisik, pengendalian stres dan therapi baik farmakologi maupun non farmakologi. Saling asuh artinya mengasuh dengan cara memberikan pendampingan bentuk tutorial berulang jika masih ditemukan pelaku rawat yang kurang memahami dari materi yang diberikan, dan silih asih yaitu saling mengasihi dengan selalu memberikan dukungan terhadap pelaku rawat jika masih ditemukan kendala atau masalah yang ditimbulkan selama mengikuti pelatihan. 
Pelatihan Manajemen Diabetes Mellitus Berbasis Budaya Sunda Untuk Meningkatkan Pengetahuan Keluarga Dalam Merawat Diabetisi Lansia Di Tasikmalaya

Siti Badriah, Dini Mariani

Selanjutnya untuk mencapai tujuan pembelajaran yang sudah ditetapkan, dilakukan penyusunan kurikulum dengan struktur pelatihan yang terdiri atas materi inti dan materi penunjang. Jumlah SKS pada pelatihan manajemen diabetes dengan pendekatan budaya Sunda sebanyak 15 SKS terdiri atas 7 SKS teori dan 5 SKS Prektek. Kegiatan pelatihan dilakukan di Aula Kecamatan Cipedes Kota Tasikmalaya selama 2 hari, dari tanggal 2 sampai 3 Desember 2018 dengan metoda ceramah dan tanya jawab, diskusi kelompok, demonstrasi, bermain peran menggunakan media modul pelatihan, laptop, LCD dan alat peraga daftar ukuran rumah tangga dan model makanan untuk pengelolaan diet DM. Sebelum dilaksanakan kegiatan pelatihan terlebih dahulu dilakukan pre-test untuk mengetahui pemahaman pelaku rawat dalam manajemen diabetes dengan pendekatan budaya Sunda. Jumlah pelaku rawat yang mengikuti pelatihan sebanyak 60 orang yang berasal dari Kecamatan Cipedes Kota Tasikmalaya.

\section{HASIL DAN PEMBAHASAN}

Analisis univariat menunjukkan mayoritas peserta pelatihan adalah perempuan dengan tingkat pendidikan SMA. Sementara itu, tingkat pendapatan di bawah UMK, hubungan kekerabatan sebagian besar sebagai anak dengan rata-rat usia 42, 14 tahun dngan usia termuda 19 tahun dan tertua 58 tahun, seperti tampak pada Tabel 1.

Tabel. 1. Distribusi Karakteristik peserta pelatihan

\begin{tabular}{llcc}
\hline & Variabel & Jumlah $(\mathrm{n})$ & Persentase (\%) \\
\hline \multirow{2}{*}{ Jenis Kelamim } & : - Laki-laki & 8 & 14 \\
& - Perempuan & 29 & 84 \\
\hline Pendidikan & : - SD & 19 & 33,3 \\
SMP & & 13 & 22,8 \\
SMA & & 22 & 38,6 \\
PT & & 3 & 5,3 \\
\hline Pendapatan & $:$ - Tidak ada & 9 & 15,8 \\
& - - UMK & 29 & 50,9 \\
& - $\geq$ UMK & 19 & 33.3 \\
\hline \multirow{2}{*}{ Hubungan } & - Anak & 46 & 80,7 \\
& - Pasangan & 9 & 15,7 \\
& - Kakak/Adik & 1 & 1,8 \\
& - Cucu & 1 & 1,8 \\
\hline & & Mean (SD) & Median (Range min-max) \\
\hline Umur & & 42,14 (10,89) & 43 (19-58) \\
\hline
\end{tabular}

Selanjutnya Gambar 1 menjelaskan tentang tentang nilai pre-test dan post-test pelaku rawat pada pelatihan manejmen diabetes dengan pendekatan budaya Sunda. 


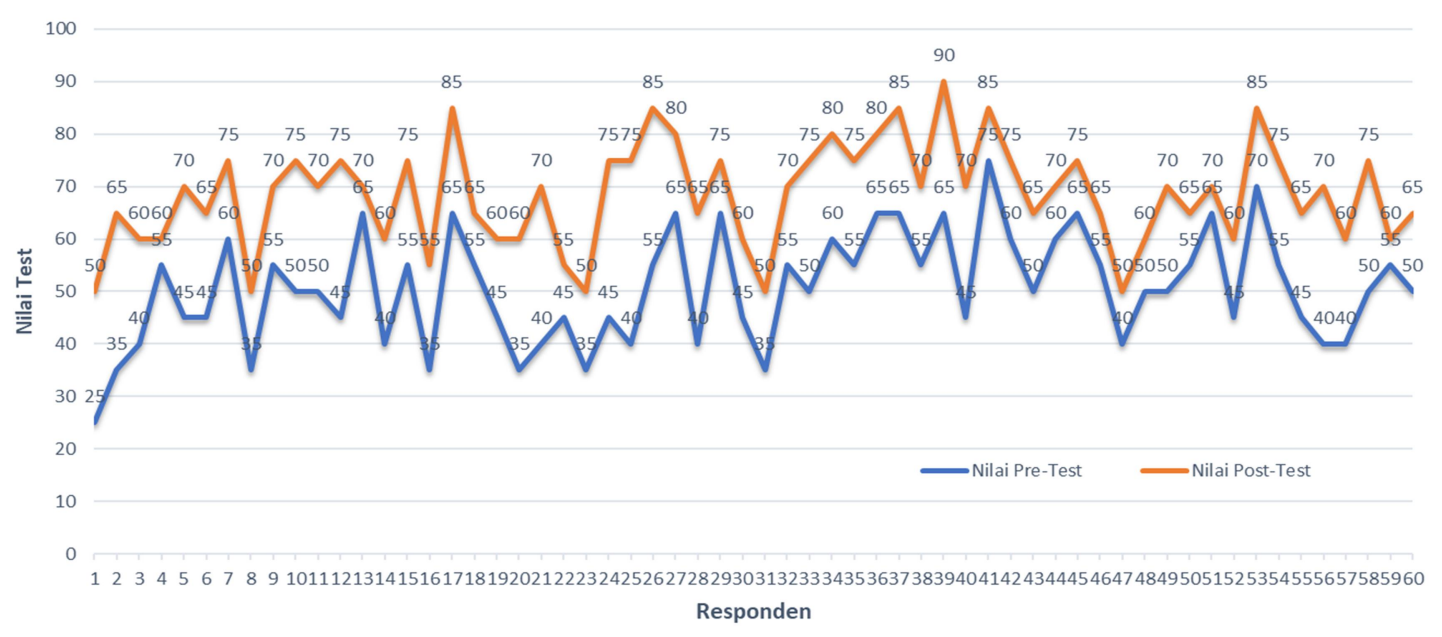

Gambar 1. Grafik Nilai pre test dan post test individu pada pelatihan pelaku rawat

Gambar 1 menunjukkan bahwa semua individu peserta pelatihan pelaku rawat mengalami peningkatan pengetahuan. Selanjutnya perubahan pengetahuan secara aggregate disajikan pada Gambar 2.

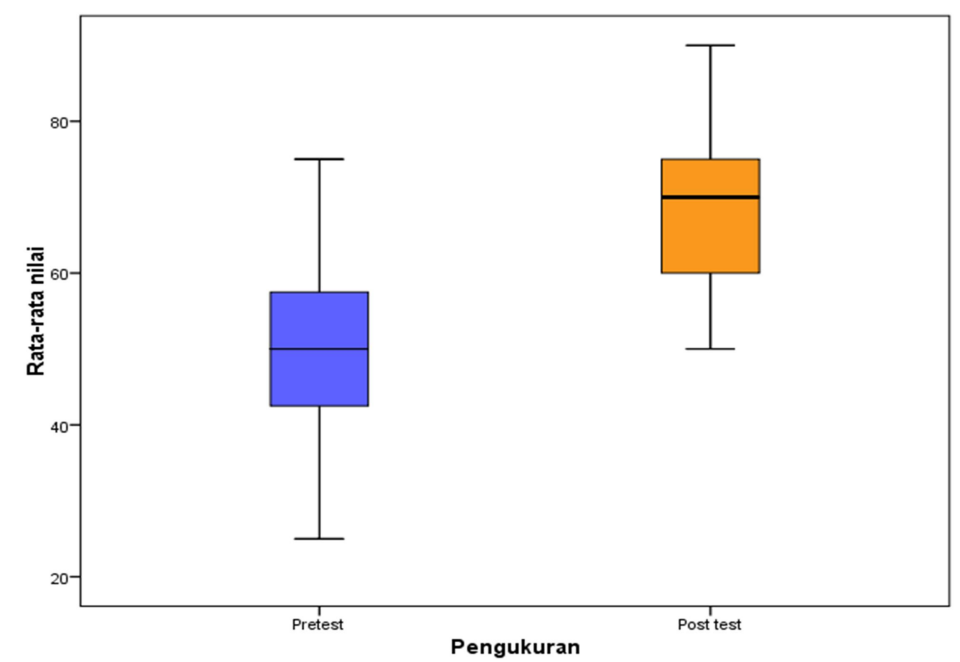

\section{Gambar 2. Perubahan nilai rerata pre test dan post test kelompok pelaku rawat}

Gambar 2 menunjukkan bahwa pada pre-test median membagi 2 sama besar dan simetris. Sementara itu, pada post-test terjadi pergeseran mendekati kuartil 3 sehingga menjadi tidak simetris. Hal tersebut menunjukkan bahwa terjadi pergeseran pengetahuan pelaku rawat menjadi lebih baik

Peningkatan pengetahuan pelaku rawat setelah diberikan pelatihan ini sesuai dengan Rustam dkk (2020) yang melaporkan bahwa terjadi perbedaan tingkat pengetahuan tentang bullying pada SMK Kesehatan Nusantara Surabaya sebelum dan sesudah dilaksanakannya 
Pelatihan Manajemen Diabetes Mellitus Berbasis Budaya Sunda Untuk Meningkatkan Pengetahuan Keluarga Dalam Merawat Diabetisi Lansia Di Tasikmalaya

Siti Badriah, Dini Mariani

penyuluhan tentang konsep dasar bullying, hal ini dibuktikan dengan adanya perbedaan nilai rata-rata sebelum dilaksanakan penyuluhan sebesar 8,81 , dan setelah dilaksanakan penyuluhan nilai rata-rata naik menjadi 11,38. Hal yang sama disampaikan oleh Ballesteros et al (2014) bahwa kegiatan pelatihan yang diberikan kepada orang dewasa cenderung dapat meningkatkan pengetahuan.

Pada kegiatan pengabdian masyarakat ini peserta pelatihan memiliki latar belakang pendidikan yang bervariasi, diantaranya masih ada $16,7 \%$ atau sekitar 10 dari 60 orang peserta pelatihan yang masih berpendidikan SD. Namun demikian, melalui modifikasi strategi pembelajaran diantaranya menggunakan strategi pembelajaran orang dewasa dengan menghargai pengalaman pelaku rawat selama merawat lansia sebagai entry point memulai suatu materi. Penyampaian materi dibuat seaplikatif mungkin disinkronkan dengan permasalahan keluarga terkait kebiasaan lansia yang selama ini dilakukan, ketika didapatkan pengalaman yang tidak tepat, maka dimulailah dengan pendalaman materi menggunakan bahasa yang lebih dipahami oleh peserta sesuai dengan modul yang dijadikan acuan oleh peserta.

Pada kegiatan pelatihan ini sering kali pemateri mengulang topik bahasan yang sama yang belum dipahami oleh peserta dalam 2 versi bahasa Indonesia maupun bahasa Sunda sesuai dengan yang dipahami oleh peserta. Hasilnya pemahaman pelaku rawat menjadi meningkat terbukti dengan adanya perubahan nilai rerata pengetahuan pada hampir seluruh individu peserta pelatihan dengan rerata kenaikan nilai post-test terhadap pre-test sebesar $38,81 \%$. Selain itu, berdasarkan pengamatan secara aggregate tampak terjadi pergeseran pemahaman peserta pelaku rawat setelah diberikan pelatihan menjadi lebih baik. Hal ini sesuai dengan hasil penelitian Sukiarko (2007) yang melaporkan bahwa latar belakang pendidikan tidak berpengaruh terhadap hasil pelatihan dimana terjadi peningkatan skor pengetahuan post test pada peserta pelatihan di Posyandu Kecamatan Tempuran Kabupaten Magelang dengan metode belajar berdasarkan masalah. Gambar 3, 4, 5, 6, dan 7 menunjukkan dokumentasi rangkaian kegiatan pelatihan manajemen diabetes dengan pendekatan budaya Sunda. 


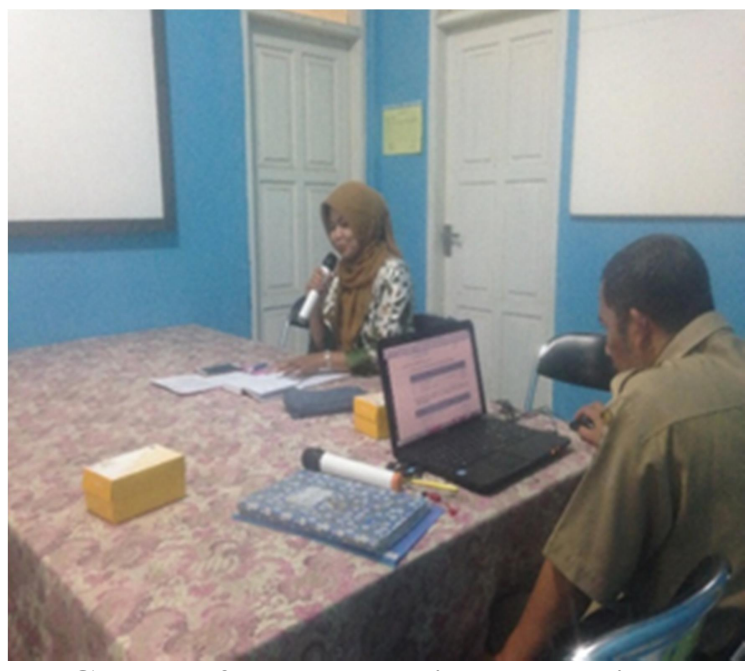

Gambar 3. Rapat persiapan pelatihan dengan aparat kecamatan Cipedes dan petugas Puskesmas Cigeureung

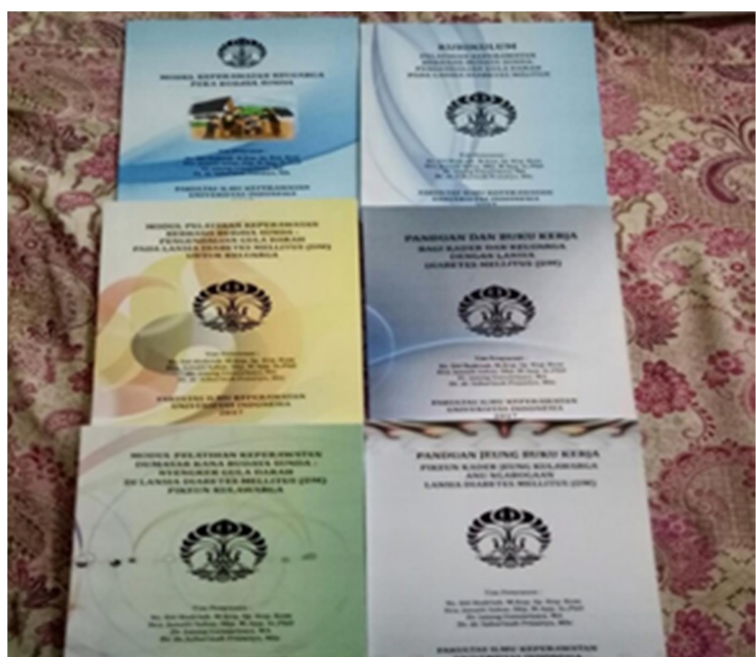

Gambar 4. Modul dan buku kerja pelatihan manajemen diabetes dengan pendekatan budaya Sunda

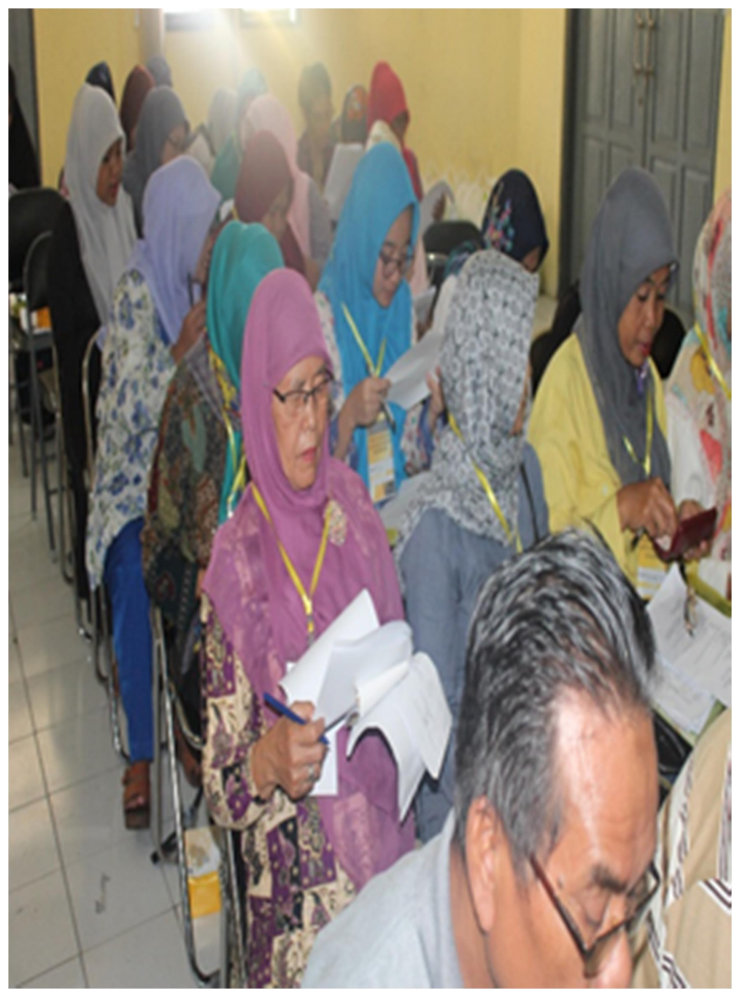

Gambar 5. Pre-test

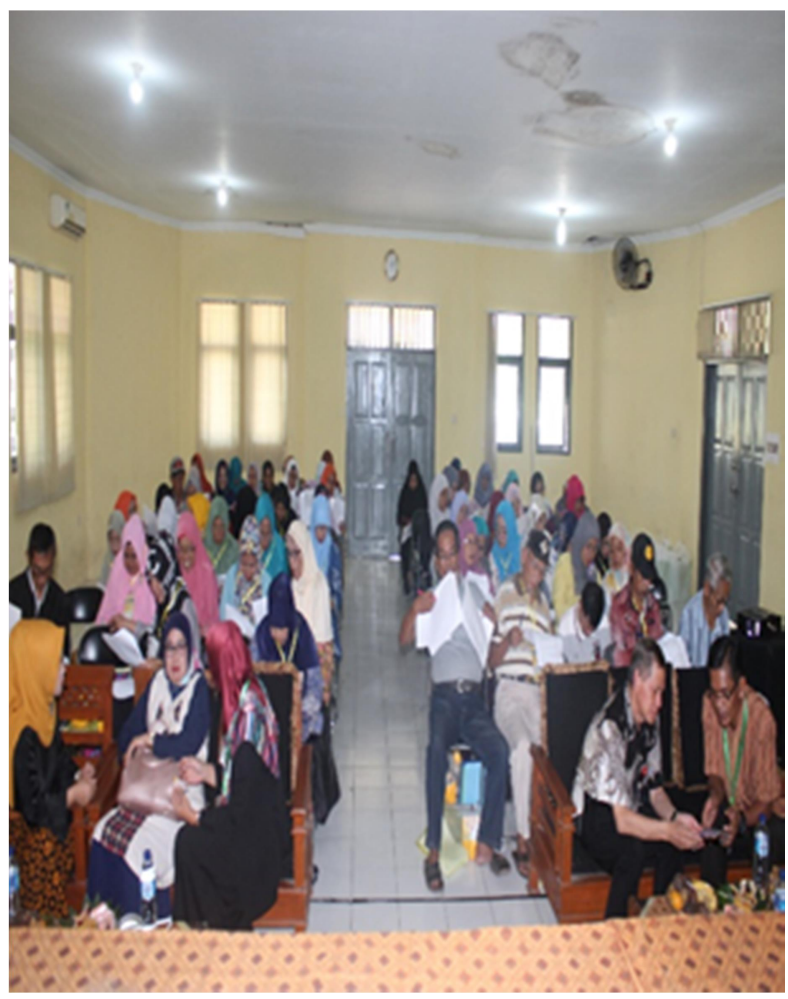

Gambar 6. Post-test 
Pelatihan Manajemen Diabetes Mellitus Berbasis Budaya Sunda Untuk Meningkatkan Pengetahuan Keluarga Dalam Merawat Diabetisi Lansia Di Tasikmalaya Siti Badriah, Dini Mariani
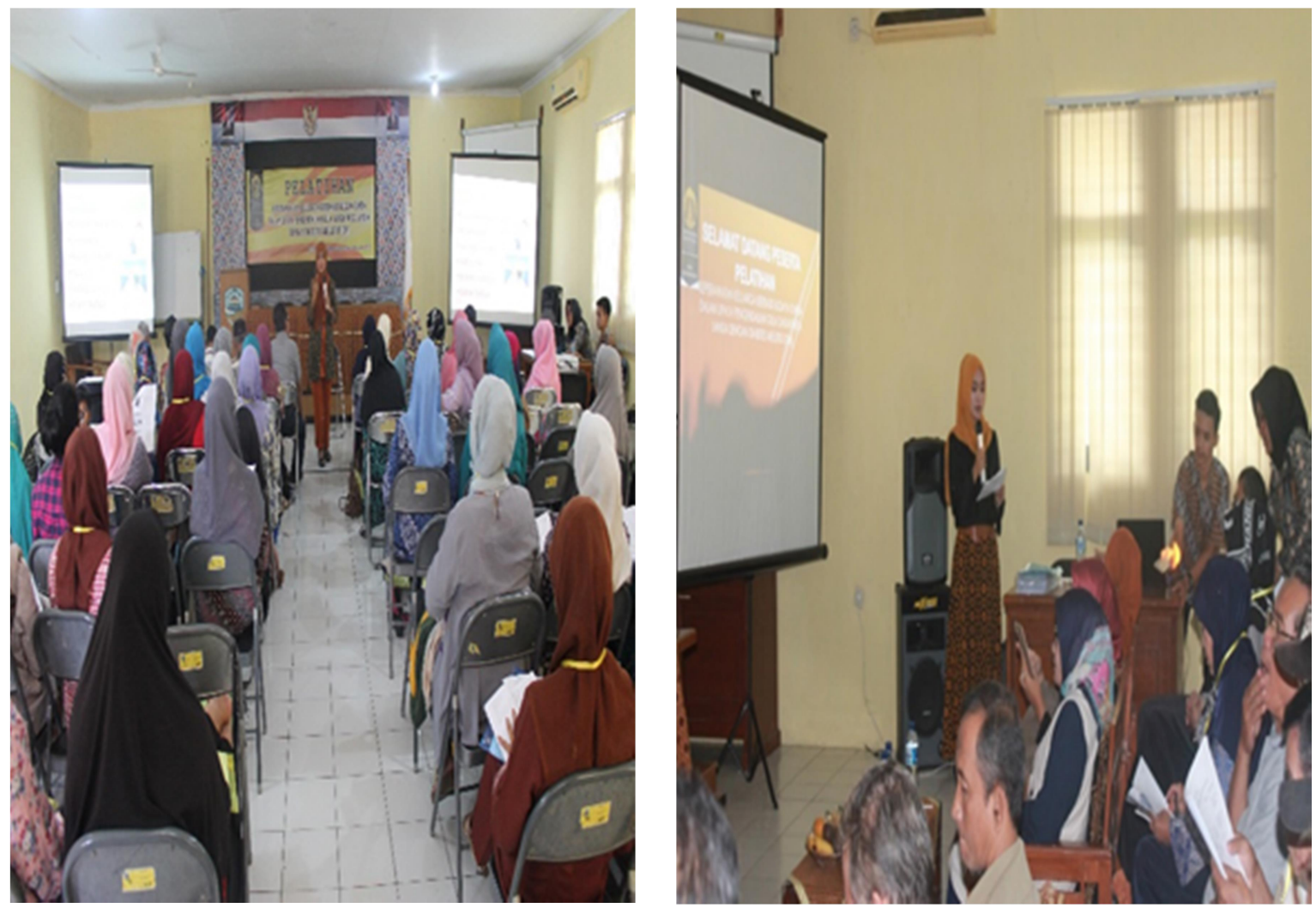

Gambar 7. Pemberian materi manajemen diabetes dengan pendekatan budaya Sunda

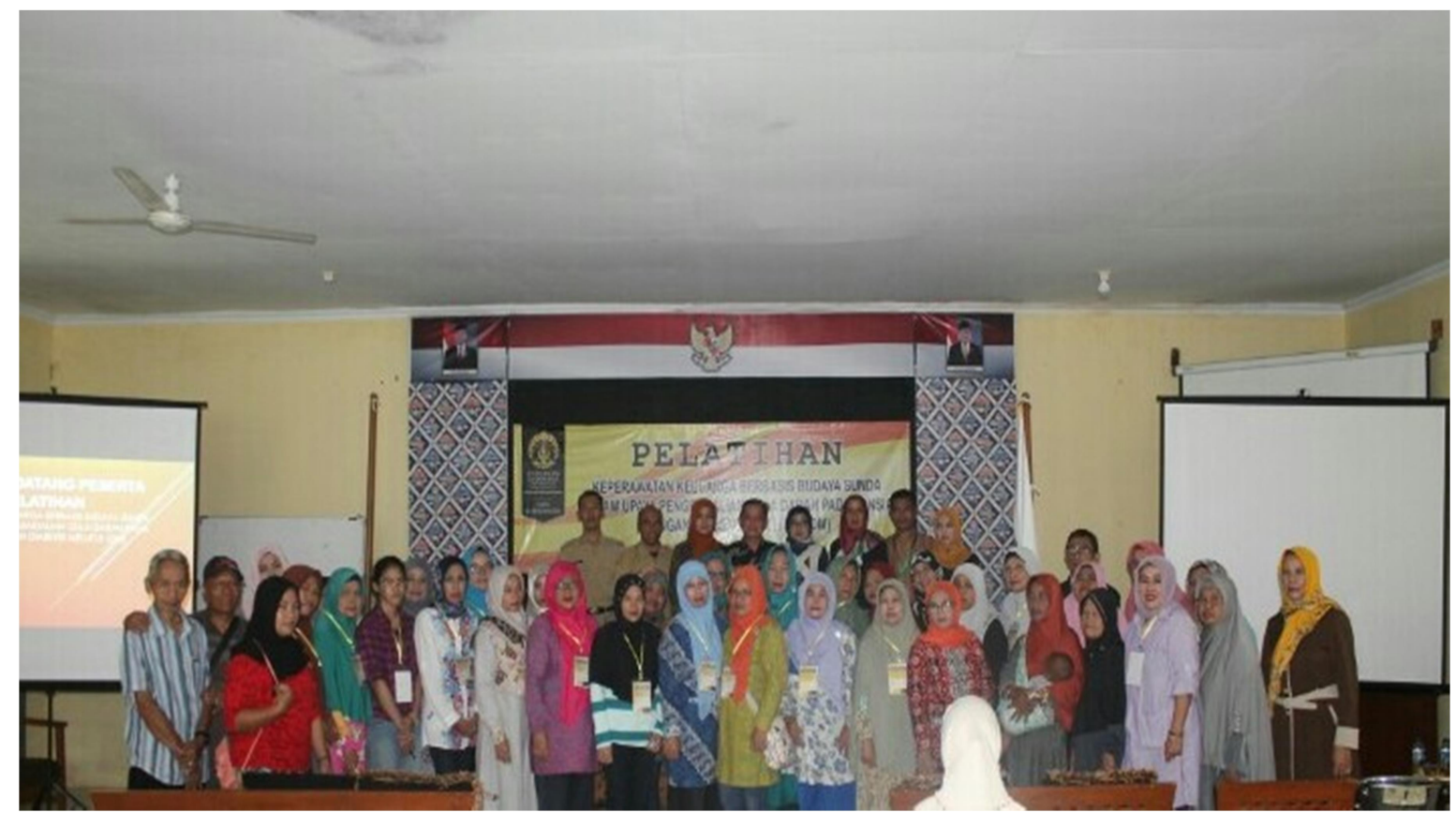

Gambar 8. Kegiatan penutupan pengabdian kepada masyarakat (penutupan pelatihan) 


\section{KESIMPULAN DAN SARAN}

Pelatihan manajemen diabetes dengan pendekatan budaya Sunda: silih asah, asuh dan asih terbukti efektif dalam meningkatkan pengetahuan keluarga dalam merawat diabetisi lansia. Pelatihan dengan pendekatan budaya ini dapat dan dijadikan sebagai pola pembelajaran dalam penanganan penderita PTM yang etiologinya memiliki kemiripan dengan diabetes mellitus.

\section{UCAPAN TERIMAKASIH}

Ucapan terima kasih kami sampaikan kepada Poltekkes Kemenkes Tasikmalaya atas dukungannya untuk terlaksanakanya kegiatan Pengabdian Masyarakat, Dinas Kesehatan Kota Tasikmalaya, Kecamatan Cipedes dan Puskesmas Cigeureung atas fasilitasinya dalam rangkaian kegiatan pengabdian masyarakat, Kader kesehatan dan seluruh peserta pelatihan (pelaku rawat) diabetisi lansia kecamatan Cipedes yang telah berkontribusi dalam kegiatan pengabdian masyarakat.

\section{DAFTAR PUSTAKA}

Badan Pusat Statistik. (2019). Statistik Indonesia 2019. (S. I. Statistik, Ed.). Jakarta: Badan Pusat Statistik.

Badriah, S., \& Sahar, J. (2017). Family support in caring for older people with diabetes mellitus: a phenomenology study. Enfermería Clínica, 27(1), 245-249. https://doi.org/10.1016/S1130-8621(18)30077-9

Badriah, S., Sahar, J., Gunawijaya, J., \& Prasetyo, S. (2019). Pampering older people with diabetes in Sundanese culture: A qualitative study. Enfermeria Clinica, 29(Insc 2018), 733-738. https://doi.org/10.1016/j.enfcli.2019.04.111.

Badriah, S., Wiarsih, W \&Permatasi, H., (2014). Pengalaman keluarga dalam merawat lanjut usia dengan diabetes mellitus. jki.ui.ac.id. https://dx.doi.org/10.7454/jki.v17i2.401

Ballesteros, S., Prieto, A., Mayas, J., Toril, P., Pita, C., Ponce de Le $\tilde{A}^{3} n$, L., ... Waterworth, J. (2014). Brain training with non-action video games enhances aspects of cognition in older adults: a randomized controlled trial. Frontiers in Aging Neuroscience, 6(OCT), 1-14. https://doi.org/10.3389/fnagi.2014.00277

Ekajati, E. S. (2014). Kebudayaan sunda suatu pendekatan sejarah. Bandung: Pustaka Jaya.Pusat Studi Sunda.

Friedman. M, Bowden V.R, \& Jones, E. (2010). Family nursing: research, theory and practice. New Jersey: Upper Saddle River, N.J. : Prentice Hall.

Haviland, W. A., Prins, H. E. L., Walrath, D., \& McBride, B. (2014). Anthropology. The Human Challenge. Journal of Chemical Information and Modeling. https://doi.org/10.1017/CBO9781107415324.004

Kemenkes. (2018). Hasil Utama Riskesdas 2018. Jakarta.

Leininger, M., \& McFarland, M. R. (2002). Transcultural Nursing: Concepts, Theories, Research, and Practice (3rd ed.). McGraw-Hill Education / Medical.

Novieastari, E., Nurachmah, E., Irawaty, D., Sudarti (2013). Efektivitas asuhan 
keperawatan peka budaya (AKPB) dalam meningkatan kepuasaan pasien Diabetes Mellitus di RS Fatmawati, Jakarta (Disertasi tidak dipublikasikan). Depok: Universitas Indonesia.

Riasmini, M., Kamso, S., Sahar, J., \& Prasetyo, S., (2013). Efektivitas model kelompok keluarga mandiri untuk meningkatkan kualitas hidup lanjut usia di masyarakat wilayah DKI Jakarta. (Disertasi tidak dipublikasikan). Depok: Universitas Indonesia. Rosidi, A. (1984). Ciri-Ciri Manusia dan Kebudayaan sunda. Jakarta: Girimukti Pasaka.

Rumoharbo, H., Sitorus, R., Irawaty, D., \& Prasetyo, S., (2012). Efektifitas model pemberdayaan"SESAMA" dalam memperbaiki pola makan dan pola latihan fisik dalam upaya mengendalikan kadar glukosa darah penyandang prediabetes (Disertasi tidak dipublikasikan). Depok: Universitas Indonesia.

Rustam dkk. (2020). Peningkatan kesehatan remaja melalui penyuluhan tentang perilaku bullying di smk kesehatan nusantara surabaya. Abdimas Galuh 2(2), 92-98.

Satjadibrata. (2005). Kamus Basa Sunda (1st ed.). Bandung: Kiblat buku utama.

Stanhope, M., \& Lancaster, J. (2016). Public Health Nursing (9th ed.). Mosby Elsevier.

Stanley, M., \& Beare, P. G. (2007). Buku Ajar Keperawatan Gerontik (Juniarti \& Kurniasih :alih bahasa). Jakarta: Penerbit Buku Kedokteran EGC. 